\title{
Manejo integral de banda gástrica secundario a migración. Reporte de caso
}

\author{
Alfredo Chama-Naranjo ${ }^{1 *}$, Andrés de J. Sosa-López ${ }^{2}$ y Jorge Farell-Rivas ${ }^{1}$ \\ ${ }^{1}$ Servicio de Cirugía General; ${ }^{2}$ Servicio de Endoscopia. Hospital Central Sur de Alta Especialidad, PEMEX, Ciudad de México, México
}

\section{Resumen}

La banda gástrica ajustable laparoscópica puede presentar complicaciones como la migración, la perforación y la erosión. El tratamiento endoscópico puede resolver las complicaciones de forma mínimamente invasiva con alta tasa de éxito.

Palabras clave: Cirugía bariátrica. Banda gástrica. Complicaciones. Tratamiento de complicaciones.

\section{Migrated gastric band: An integrated approach. A case report}

\begin{abstract}
\section{Introducción}

La banda gástrica ajustable laparoscópica (BGAL) presenta complicaciones como migración, perforación, penetración y erosión, que se presentan en un $2.2-10 \%$, $1.8-6.6 \%$ y $0.3-11 \%$, respectivamente'.

Se describe un caso de colocación de banda gástrica «artesanal» que presentó migración y erosión intraluminal (penetración).
\end{abstract}

Laparoscopic adjustable gastric band may present complications such as migration, perforation and erosion. Endoscopic treatment is able to solve the complications in a minimally invasive manner with high rate of success.

Key words: Bariatric surgery. Gastric band. Complications. Complication treatment.

\section{Caso clínico}

Mujer de 40 años con antecedente de colocación de BGAL por abordaje abierto (extrainstitucional).
Presentó índice de masa corporal (IMC) preoperatorio de $38 \mathrm{~kg} / \mathrm{m}^{2}$, alcanzó un IMC de $32 \mathrm{~kg} / \mathrm{m}^{2}$ al primer año y cinco años después se documenta un IMC de $34 \mathrm{~kg} / \mathrm{m}^{2}$. Presenta síntomas digestivos de dos meses de evolución caracterizados por distensión abdominal recurrente y dolor abdominal con la ingesta de alimentos. Se realiza panendoscopia y tomografía contrastada, encontrando penetración intraluminal de la banda gástrica a nivel del cardias mayor al $50 \%$ de su circunferencia (Fig. 1 A-C).

Se decidió la retirada de la BGAL por abordaje endoscópico, por medio de un litotriptor tipo Soehendra y bajo visión endoscópica se lazó la banda gástrica 


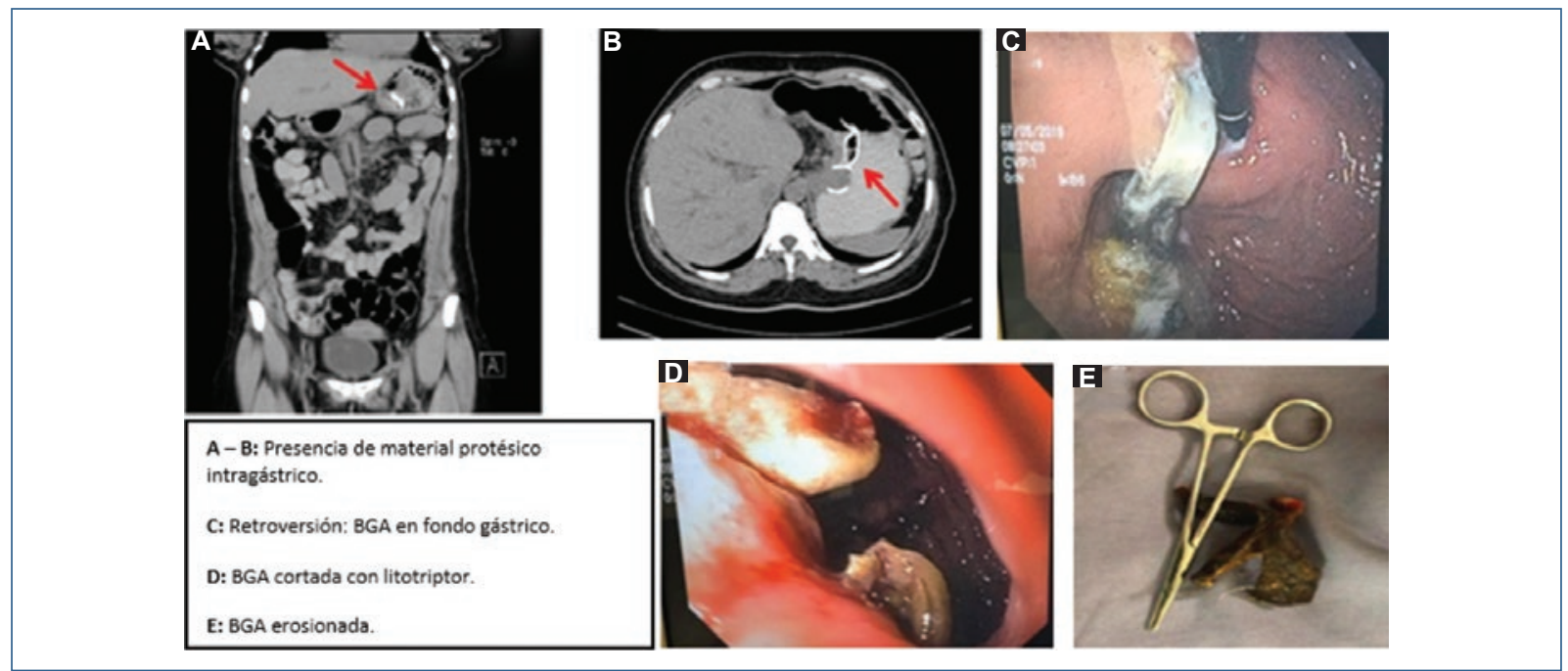

Figura 1. A-B: presencia de material protésico intragástrico. C: retroversión (BGAL en fondo gástrico). D: BGAL cortada con litotriptor. E: BGAL erosionada. BGAL: banda gástrica ajustable laparoscópica.

hasta su rotura (Fig. 1 D); se extrajo a través de la boca con asa de polipectomía sin complicaciones (Fig. 1 E).

\section{Discusión}

La migración y erosión intragástrica son complicaciones en las que se encuentran involucrados diversos mecanismos. Cuando se presentan de forma temprana generalmente son debidos a problemas técnicos tras su colocación ${ }^{2}$.

Los síntomas descritos en la erosión gástrica son dolor epigástrico e infección persistente del puerto subcutáneo. Puede presentarse como primer síntoma el aumento del peso perdido secundario a la ausencia del mecanismo de restricción de la banda ${ }^{3}$.

La tomografía contrastada es la modalidad de elección para el diagnóstico, ya que permite identificar la localización de la banda ${ }^{4}$. La endoscopia digestiva alta puede ser terapéutica, retirando la banda en caso de ser posible ${ }^{5}$.

El tratamiento depende de los síntomas, el estado clínico del paciente, la localización de la banda y los recursos hospitalarios disponibles. Generalmente no representa una urgencia quirúrgica ${ }^{6}$.

En caso de migración, el tratamiento va a depender de la clínica y el tipo de penetración de la banda. Si la banda se encuentra dentro del esófago/estómago en más del $50 \%$ de su circunferencia, puede intentarse su retirada vía endoscópica?.
Nuestro caso presentó migración con erosión cinco años después de su colocación, cuyo tratamiento fue factible realizarlo por endoscopia terapéutica.

\section{Conclusión}

En los años noventa, se colocaron un importante número de bandas gástricas «artesanales» (con materiales como politetrafluoroetileno, látex y silicona) que no contaban con un puerto para calibración y que permanecían en el cuerpo del paciente hasta su retirada. La endoscopia puede resolverlo de forma mínimamente invasiva, con alta tasa de éxito y bajas complicaciones, como se demuestra en este reporte de caso.

\section{Financiamiento}

Los autores no recibieron patrocinio para llevar a cabo este artículo.

\section{Conflicto de intereses}

Los autores declaran no tener conflicto de intereses alguno.

\section{Responsabilidades éticas}

Protección de personas y animales. Los autores declaran que para esta investigación no se han realizado experimentos en seres humanos ni en animales. 
Confidencialidad de los datos. Los autores declaran que han seguido los protocolos de su centro de trabajo sobre la publicación de datos de paciente.

Derecho a la privacidad y consentimiento informado. Los autores han obtenido el consentimiento informado de los pacientes y/o sujetos referidos en el artículo.

\section{Bibliografía}

1. Fried M, Miller K, Kormanova K. Literature review of comparative studies of complications with Swedish band and lapband. Obes Surg. 2004;14:256-60.
2. Changela K, Ofori E, Duddempudi S, et al. Peroral endoscopic reduction of dilated gastrojejunal anastomosis after bariatric surgery: Techniques and efficacy. World J Gastrointest Endosc. 2016;Feb; 8(4): 239-43.

3. Sapalidis K, Liavas L, Panteli N, Anand S, Singhal S. Intrajejunal migration of adjustable gastric band: A case report. Curr Health Sci J. 2013;39:118-20.

4. Salar O, Waraich N, Singh R, Awan A. Gastric band erosion, infection and migration causing jejunal obstruction. BMJ Case Rep. 2013 Jan $17 ; 2013$.

5. Bueter M, Thalheimer A, Meyer D, Fein M. Band erosion and passage, causing small bowel obstruction. Obes Surg. 2006;16:1679-82.

6. Campos JM, Evangelista LF, Galvão Neto MP, Ramos AC, Martins JP, dos Santos MA Jr, et al. Small erosion of adjustable gastric band: endoscopic removal through incision in gastric wall. Surg Laparosc Endosc Percutan Tech. 2010;20:e215-7.

7. Tekin A. Migration of the connecting tube into small bowel after adjustable gastric banding. Obes Surg. 2010;20:526-9. 